\title{
Acquisition, extinction, and spontaneous recovery of conditioned suppression of licking*
}

\author{
JAMES P. JAMES \\ Fort Hays Kansas State College, Hays, Kans. 67601
}

A conditioning procedure yielding a trial-by-trial measure of the suppression of ongoing licking behavior in rats is described. In one group $(\mathrm{N}=9)$, forward pairings of CS with shock produced rapid acquisition, slow extinction, and nearly complete spontaneous recovery following a 30-day "rest" period. In a second group $(\mathrm{N}=8)$, initial backward pairings (shock-CS) produced supernormal suppression ratios. During CS-alone trials, supernormal performance was shown by both the backward group and a third group $(\mathrm{N}=8)$, which received initial free-shock trials.

Some advantages of using ongoing licking at a drinking tube, in place of barpressing, as the baseline in conditioned suppression experiments were discussed by Leaf \& Muller (1965) and Vogel \& Spear (1966). The procedure used by these investigators, however, provided only a one-trial test of the strength of response suppression. James \& Mostoway (1968) described a consummatory response-based procedure that yielded, for acquisition and extinction, a trial-by-trial record of response suppression similar to measures obtained with the Estes-Skinner operant-response-based method (Estes $\&$ Skinner, 1941). The results of the James and Mostoway study, that acquisition and resistance to extinction were positively related to the intensity of shock used during training, were consistent with the findings of Annau \& Kamin (1961), who used the Estes-Skinner procedure to examine the shock-intensity parameter.

One purpose of the present study was to investigate further the conditioned suppression of licking procedure by including, in addition to a forward conditioning group, backward and UCS-alone control groups. Predicting from Kamin's (1963) data on suppresssion of operant responses, the backward control group should develop supernormal suppresssion ratios during trials of backward pairings. Based on the results of Brimer \& Kamin (1963), the $\mathrm{CS}$ would be expected to produce response facilitation following UCS-alone (free shock) presentations.

* This research was conducted at the University of Manitoba and was supported by Grant APA-223 from the National Research Council of Canada. The assistance of Charles Burdick and Walter Mostoway during the spontaneous recovery phase is gratefully acknowledged.
A second purpose was to determine if this licking-based conditioning procedure would produce, in addition to acquisition and extinction, another well-established conditioning phenomenon, spontaneous recovery.

\section{METHOD}

The Ss were 27 naive male Sprague-Dawley *rats, approximately 90 days old at the start of the experiment. During the course of the experiment two $\mathrm{Ss}$, one from each control group, were discarded for failure to drink during the conditioning sessions.

The apparatus consisted of three conditioning units, similar to the one described in detail by James \& Mostoway (1968). Each unit consisted of a conditioning chamber (Scientific Prototype A-100) set inside a sound-attenuated enclosure (Lehigh Valley A-64). Access to the drinking tube of a water bottle was gained through a hole in the center of one wall, $5 \mathrm{~cm}$ above the grid floor. Tongue contacts with the drinking tube in each chamber were detected by Grason-Stadler drinkometers (E4690A-L) and recorded on electromechanical counters. By remotely opening or closing a circuit to a solenoid, the water bottle would swing toward the chamber, making the drinking tube accessible to $S$, or away from the chamber out of S's reach. Each bottle was filled with fresh tap water. White noise from a Grason-Stadler 901B generator was the CS. Grid shock in each chamber was produced by separate Grason-Stadler shock generators (E1064GS). One GE 1829 incandescent lamp, operated at $18 \mathrm{~V} \mathrm{dc}$, was located at the rear of each chamber and provided continuous illumination.

Pretraining consisted of 5 days of adaptation to water deprivation (water bottles on each home cage for $20 \mathrm{~min}$ each day) and four subsequent daily adaptation sessions in the conditioning chamber. During the initial two $20-\mathrm{min}$ adaptation sessions in the chamber, the spout of the water bottle was accessible to $\mathrm{S}$ for only the final $15 \mathrm{~min}$. The third and fourth sessions of chamber adaptation were $15 \mathrm{~min}$ in length with the drinking tube available during the final $10 \mathrm{~min}$. Ten 30 -sec habituation trials of the potential CS were given to all Ss on the fourth day of chamber adaptation. All sessions thereafter were $15 \mathrm{~min}$ long, with water available during the final $10 \mathrm{~min}$.

The CS was a 30 -sec white noise of $82 \mathrm{~dB}$. Onset of the CS occurred randomly, $2,2 \frac{1 / 2}{2}, 3,3 \frac{1 / 2}{2}$ or $4 \mathrm{~min}$ (mean $=3 \mathrm{~min})$ after water bottle presentation. The UCS was a $0.5-\mathrm{sec}$, $0.8 \cdot \mathrm{mA}$ shock. For forward conditioning, CS onset preceded UCS onset by 30 sec. For backward conditioning, UCS offset and CS onset were simultaneous. The Ss which received the UCS-alone were treated as those receiving forward pairings, except no CS was presented during the first 10 trials. One trial each day was administered to all Ss.

The groups received the experimental treatments as follows. Group F (forward pairings) received 10 trials of CS-UCS pairings, 20 trials of CS-alone presentations, 30 days in the home cages, 5 days of testing for spontaneous recovery, 30 days in the home cages, and 3 days of testing for spontaneous recovery. Initially, Group B (backward pairings) received 10 days of UCS-CS pairings and Group U (UCS-alone) received 10 days of UCS-alone presentations. Both control groups then received 10 daily CS-alone trials. The Ss had free access to food in their individual home cages during the entire experiment. Beginning on the first day of adaptation to the chamber, the Ss received all their water in the conditioning boxes. For Group F, during the recovery intervals, water was available in the home cages for $15 \mathrm{~min}$ each day.

In addition to recording the number of responses produced during the 30-sec CS, responses were summarized during preCS and postCS periods occurring $30 \mathrm{sec}$ before and $30 \mathrm{sec}$ after the $C S$, respectively. Individual suppression ratios, indicating the fraction of the total responses produced during both preCS and CS that was elicited during the $C S$, were calculated according to $\mathrm{B} /(\mathrm{A}+\mathrm{B})$ where $A$ represents preCS responses and $B$ represents $C S$ responses. For Group $U$ on Trials 1-10, the "CS" period is the 30 -sec interval preceding shock and the pre "CS" and post"CS" periods are the 30 -sec intervals preceding and following the "CS," respectively. 


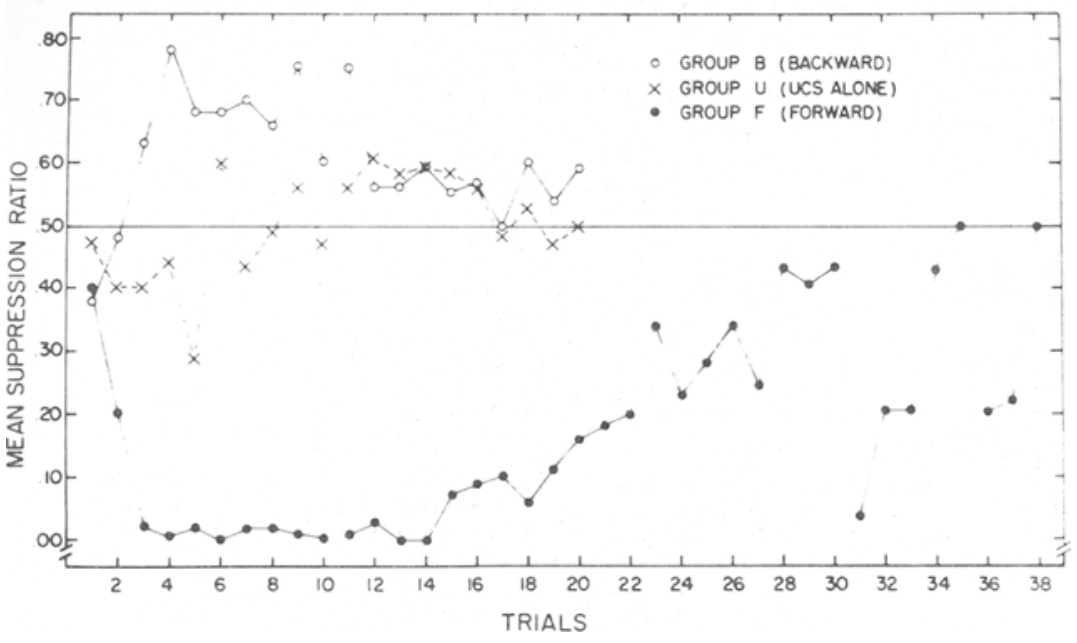

Fig. 1. Mean suppression ratios across daily trials.

\section{RESULTS}

Figure 1 shows mean suppression ratios plotted across Trials 1-20 for Groups $B$ and $U$ and plotted across Trials 1-38 for Group F. The results are also presented in Fig. 2, which portrays for each group the mean number of licking responses produced during the periods of preCS, CS, and postCS on each of Trials 1-20. Because of apparatus failure, three scores from Group $\mathrm{F}$ and two scores from Group B were lost.

Figure 1 shows clearly that across Trials 1-20, Group F behaved differently from the two control groups. On Trials 9-15 there was no overlap of suppression ratios or of CS scores (the number of responses produced during the $\mathrm{CS}$ ) between Ss of Group $F$ and the control animals. All Ss in Group F had lower suppression ratios and CS scores on Trial 3 as compared to Trial 1.
Inspection of Fig. 1 reveals that maximum conditioning occurred on Trial 3 after two CS-UCS pairings, while extinction required approximately 20 CS-alone presentations.

As shown in Fig. 1, during the first 10 trials Group B developed supernormal suppression ratios which differed reliably from the suppression ratios of Group $U$ ( $F=17.59$, $\mathrm{df}=1 / 14, \quad \mathrm{p}<.001)$. Group U's suppression ratios here provide a kind of baseline indicating preshock performance that occurs in the absence of the CS. Figure 2, however, shows that what appeared as facilitated performance in Group B on the basis of suppression ratio scores is actually normal responding in the CS preceded by partially suppressed preCS responding.

During the acquisition trials there was a trend for an overall reduction in
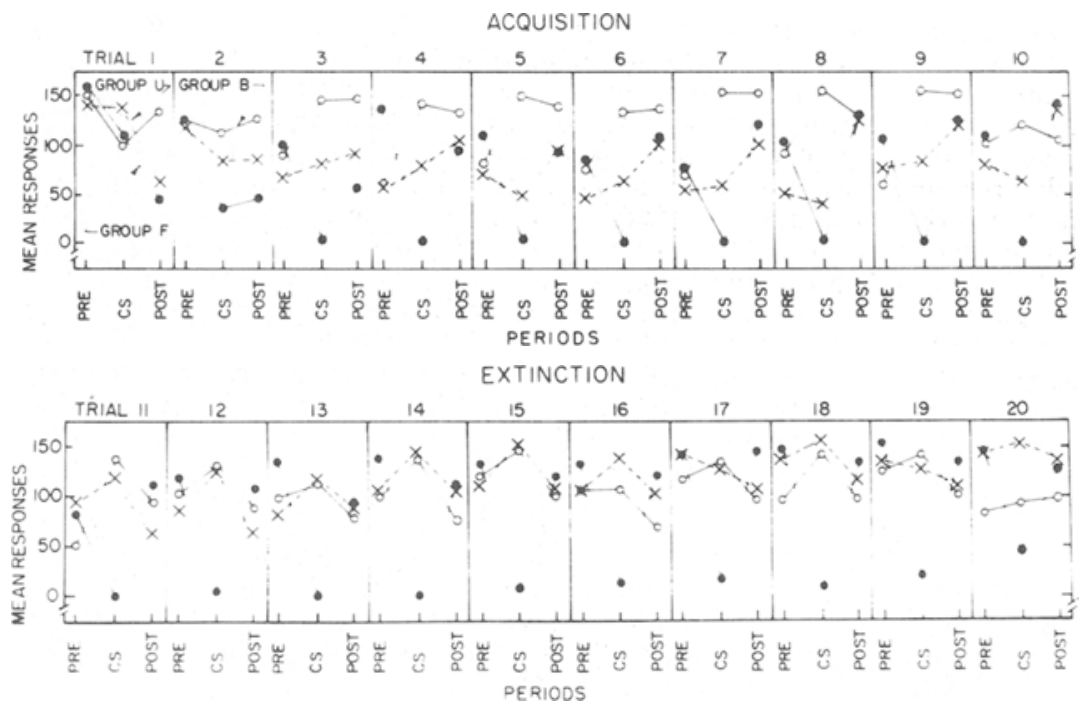

Fig. 2. Mean responses during preCS, CS and postCS periods for each group on each daily trial of acquisition and extinction.
preCS responding $(\mathrm{F}=7.82$, df $=9 / 197, \quad p<.001)$. The preCS baseline of Group $F$ was significantly higher than that of Group B $(t=2.52$, $\mathrm{df}=15, \mathrm{p}<.05)$ and that of Group $\mathrm{U}$ $(t=4.66, \quad d f=15, \quad p<.001)$. The control groups did not differ in preCS responding.

Figures 1 and 2 show the similarity of the control groups' facilitated CS performance across Trials 11-20. Separate 2 by 10 (preCS vs CS by Trials 11-20) analyses of variance, conducted on each control group, indicated that $\mathrm{CS}$ responding was significantly higher than preCS responding for Group $B \quad(F=11.25$, $\mathrm{df}=1 / 7, \quad \mathrm{p}<.025)$ and Group $\mathrm{U}$ $(\mathrm{F}=8.17, \quad \mathrm{df}=1 / 7, \quad \mathrm{p}<.025)$. Although overall increases in the preCS $(\mathrm{F}=3.97$, df $=9 / 196, \mathrm{p}<.001)$ and postCS $(F=2.82, \quad \mathrm{df}=9 / 196$, $\mathrm{p}<.005$ ) baselines occurred for all three groups during the extinction trials, the groups did not differ significantly in their preCS or postCS responding.

Figure 1 indicates that spontaneous recovery from extinction was virtually complete on Trial 31,30 days after the final extinction trial. For Group F, each S's suppression ratio decreased from Trial 30 to Trial 31. Performance on Trial 31 did not differ significantly from that of the final day of acquisition. The mean percentage spontaneous recovery on Trial 31 was $91.7 \%$. With the exception of one S that showed $28.9 \%$ recovery, all Ss exhibited spontaneous recovery of conditioned suppression in excess of $98 \%$. Figure 1 shows that the course of extinction following spontaneous recovery (Trials 31-35) occurred rapidly as compared to the 20 trials of initial extinction. On Trial 36 , recovery of the conditioned response occurred again after a second 30-day "rest" interval (Trial 35 vs Trial 36 : $\mathrm{A}=.161, \mathrm{df}=8, \mathrm{p}<.01)$ but not to the degree of the first recovery (Trial 31 vs Trial $36: A=.221$, df $=8$, $\mathrm{p}<.05)$. Extinction following the second recovery interval occurred after two CS presentations.

\section{DISCUSSION}

The present findings appear consistent with the results of studies in which operant responding is used as the baseline. During the initial 10 trials of the study reported here, the backward control group developed supernormal suppresssion ratio scores like those of Kamin (1963). Furthermore, following free shock trials the UCS-alone control group responded more during the "CS" as compared to a pre "CS" baseline period. This compares favorably with results of Brimer \& Kamin (1963). 
The group receiving forward pairings showed the kind of performance that would be expected for conditioned autonomic responses (Beecroft, 1967). Rapid acquisition was followed by relatively slow extinction. Moreover, spontaneous recovery, a well-established conditioning phenomenon, was clearly demonstrated. Estes \& Skinner (1941) found nearly complete spontaneous recovery of conditioned suppression of barpressing following a 24-h recovery interval. The 24-h intertrial interval used in the present study obviated the occurrence of spontaneous recovery for that period of time. But it is clear that the first 30-day recovery interval was sufficiently long to produce greater than $90 \%$ spontaneous recovery fiom extinction. Significantly less spontaneous recovery was produced by the second 30-day recovery interval.

Although further support is thus advanced to indicate that ongoing licking is an adequate baseline for use in a trial-by-trial investigation of conditioned suppression, the procedure is not without its weaknesses. One problem, mentioned elsewhere (James \& Mostoway, 1968), concerns the fairly rapid decrease in mean baseline responding that occurs across the 10-min drinking sessions. This necessitates presenting the stimuli during the first $5 \mathrm{~min}$ of the session, with the resulting problem that the Ss may form a discrimination and suppress responding until they receive shock. Such suppression would be recorded as zeros during the preCS and CS periods. To insure licking early in the session, one solution used here has been to provide a 5 -min predrinking period when the drinking tube is inaccessible to Ss. Then the stimuli are presented at varying times after the drinking tube is made accessible. No zero preCS scores were obtained in the present investigation. Another problem is whether the daily $10-\mathrm{min}$ drinking period is of sufficient length for Ss to obtain an adequate quantity of water. Aithough no measure of body weight was taken, by incidental observation it was noted that the Ss appeared thin but not emaciated. With respect to interS variability, it should be pointed out that it is usually not necessary to use blocks of trials. The data appear orderly when the mean of each daily trial is used. Finally, since the licking rate of rats appears to be either zero or a constant value (Corbit \& Luschei, 1969), the procedure does not readily lend itself to the study of response facilitation. After the Ss stabilize licking at their normal rate, response suppression from this baseline is a pause in licking. It follows that response facilitation is not possible from this invariant baseline of normal licking. Therefore, any supernormal suppression ratios obtained with this procedure would have to occur from a partially or completely suppressed baseline of licking.

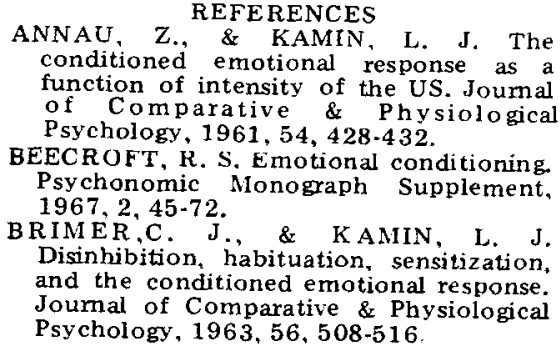
conditioned emotional response as a function of intensity of the US. Joumal of Comparative \& Physiological Psychology, 1961, 54, 428.432.

BEECROFT, K. S. Emotional conditioning. Psychonomic Monograph Supplement, $1967,2,45-72$.

BRIMER,C. J., \& KAMIN, L. J. Disinhibition, habituation, sensitization, and the conditioned emotional response. Joumal of Comparative \& Physiological Psychology, 1963, 56, 508-516.

CORBIT, J. D. \& LUSCHEI. E. S. Invariance of the rat's rate of drinking. Journal of Comparative \& Physiological Psychology, 1969,69, 119-125.

ESTES, W. K., \& SKINNER, B. F. Some quantitative properties of anxiety. Joumal of Experimental Psychology, $1941,29,390-400$

JAMES, J. P.. \& MOSTOWAY, W. W. Conditioned suppression of licking as a function of shock intensity. Psychonomic Science, 1968, 13, 161-162.

KAMIN, L. J. Backward conditioning and the conditioned emotional response. Journal of Comparative \& Physiological Psychology, 1963.56,517-519.

LEAF, R. C., \& MULLER, S. A. Simple method for CER conditioning and measurement. Psychological Reports, 1965, 17, 211-215.

VOGEL. J, R., \& SPEAR. N. E. Interaction of reward magnitude and conditioned fear on the consummatory response. Psychonomic Science, 1966, 5, 263-264.

\title{
Performance of squirrel monkeys on systematic or random presentation of patterned string problems
}

\author{
DONALD G. HARRIS and MERLE E. MEYER \\ Western Washington State College, Bellingham, Wash. 98225
}

A comparison was made between systematic and random presentation of Harlow's Series II patterned string problems for squirrel monkeys. A nonsignificant difference was obtained between the two methods of presentation. A significant pattern effect was found and discussed in terms of a visual acuity hypothesis.

Recently, Cha \& King (1969), and Fife \& Kamback (1970) have reported learning of various patterned string problems by squirrel monkeys. However, a comparison with other primate performances on the patterned string problems is not directly possible because of various changes in procedures and in patterns. Mason \& Harlow (1961) have found that the order of presentation may affect patterned string performance. The purpose of this study was to investigate the performance on the squirrel monkey when the Harlow and Settlage Series II patterns were presented in a systematic or random sequence.

\section{SUBJECTS}

The Ss were three male and three female young adult squirrel monkeys (Saimiri sciurius) obtained from the Woodward Asiatic Company. The animals were individually housed and, prior to the experiment, were maintained on Purina Monkey Chow supplemented with fruit on alternate days. One animal died of an undetermined cause prior to the study. APPARATUS

The living-test cages were made of heavy wire mesh and were $25.4 \times 53.3 \times 53.3 \mathrm{~cm}$ with the two sides of the cages covered with plywood. The wire mesh allowed the $S$ to extend his arm or arms approximately $12 \mathrm{~cm}$ through the front of the cage.

The test apparatus was modeled from the Harlow \& Settlage (1934) string apparatus. The board was a 45.7-cm-square piece of marine plywood painted flat black and mounted on a cart. The strings were drapery cord, and small eyelets were used to position the patterns on the board. The patterns used were Harlow \& Settlage's Series II and are shown in Fig. 1.

\section{PROCEDURE}

Small banana sections were used as 